\title{
Discursos distintivos a partir da cultura material têxtil no Brasil (1847-1910)
}

\section{Discourses of Distinction on the material culture of textiles in Brazil (1847-1910)}

Luz García Neira

\section{Argumentos iniciais}

Reincidentemente, o estudo sobre os têxteis no Brasil tem sido considerado insuficiente (Paula, 2004; Andrade, 2006) para atender à demanda da pesquisa nas ciências humanas. A insignificância quantitativa de pesquisas acerca dessa espécie material é atribuída, sobretudo, à dificuldade de conservação do material têxtil em climas tropicais, em associação às políticas institucionais de conservação de têxteis, muitas vezes consideradas precárias.

Luz García Neira é doutoranda na Faculdade de Arquitetura e Urbanismo da Universidade de São Paulo (FAU-USP), São Paulo, Brasil e pesquisadora do projeto de Renovação dos Ambientes do Museu Casa de Rui Barbosa (RJ) (design.textil@uol.com.br).

Artigo recebido em 4 de maio de 2011 e aprovado para publicação em 12 de setembro de 2011. 
Uma vez que as dificuldades que envolvem a preservação de artefatos têxteis no Brasil não configuram causas, mas consequências das práticas estabelecidas, podemos nos inserir, também, nas mesmas dificuldades que são enfrentadas no contexto internacional. De maneira geral, acredita-se que, ao longo de muito tempo, se instaurou o desprezo sobre a materialidade têxtil por duas principais razões: os têxteis constituem tipologias associadas ao gênero feminino, além de, em si mesmos, terem um valor material considerado menor (Jackson, 2002), quando comparados a outros artefatos, como os produzidos em metais, pedras, madeiras etc. Essas duas razões, em teoria, foram suficientes para instaurar o desinteresse por esses objetos.

Hoje pode soar estranho esse tipo de partido se não é de nosso conhecimento o processo histórico que encobre: a desvalorização de tais artefatos pode ser atribuída à própria maneira de se fazer história, que, como se sabe, até recentemente privilegiou heróis, eventos e monumentos. Teriam sido as luzes lançadas aos objetos anteriormente tomados como menores, em virtude das postulações da Nova História, as responsáveis pela descoberta dos anônimos, do cotidiano e das espécies materiais menores e por sua transformação em fontes de pesquisa para o historiador. Deve-se relembrar que essa mudança de postura afetou não só a seleção documental, mas, também, o ofício do historiador que, no mesmo passo, pôde utilizar-se de novas metodologias, dar ouvidos à história oral, à história das mentalidades e ideias, à história da ciência etc.

Somente a partir dessa nova perspectiva é que foi possível pensar em uma História que contasse com a contribuição da cultura material da qual fazem partes os têxteis, sejam eles domésticos e/ou artesanais, artísticos ou industriais, distinção estipulada a partir da ótica do processo mental de transformação da natureza, e não somente do produto resultante como se esse fosse dado ou natural. Esse entendimento permite, também, que investigações sejam propostas a partir de qualquer tipo de

[...] evidência concreta da operação da inteligência humana no tempo de fabricação [do artefato]. A premissa destacada é que os objetos feitos ou modificados pelo homem refletem, consciente ou inconscientemente, direta ou indiretamente, as crenças de indivíduos que fazem, encomendam, vendem ou usam [os artefatos], e por extensão as crenças da sociedade à qual eles pertencem (Prown, 1982: 1-2).

A variedade tipológica têxtil, e essa é sua característica distintiva, não necessariamente corresponde à sua função prática. Ainda, os artefatos têxteis normalmente são tanto decorativos (ou estéticos) quanto utilitários (Prown, 
1982), de modo que essa distinção não é representativa nesta espécie material, demonstrando que é infértil (para as ciências humanas) o estudo do artefato têxtil por ele mesmo, sem que esteja compreendido à luz do contexto de sua existência. Assume-se, portanto, como cultura material têxtil, os artefatos que são criados, produzidos, consumidos e descartados em um dado ambiente social com a função de diferenciar e/ou humanizar ambientes e pessoas (Schoeser, 1986).

No Brasil, até então, a história dos têxteis, estudada prioritariamente como uma subcategoria da história da moda, foi abordada quase sempre pela cultura visual. O método predominante, nesse sentido, foi o de associar os estudos da linguagem aos estudos da visualidade têxtil, atribuindo a essa espécie material, quando apresentada nas roupas, o caráter de signo. A partir de possíveis significações imputadas a priori, a visualidade dada pela matéria tornou-se, na maioria das vezes, protagonista da História. De certa forma é o que Ulpiano Bezerra de Meneses (2003) entende por dar à visualidade, como tipo de fonte, o caráter de objeto ou substância para o historiador, ao invés de tomá-la como uma "plataforma de observação" para se ter acesso a outros tipos de fenômenos.

Os novos estudos que adotam a postura da cultura material representam, portanto, uma nova opção à corrente até então dominante. Os variados artefatos têxteis que, sem dúvida, possuem uma dimensão visual importante, em "[...] suas configurações ou propriedades [...] correspondem às crenças padronizadas de um produtor ou produtores, na sociedade da qual eles tomam parte" (Prown, 1983: 6), permitindo que o conhecimento histórico independa de sua conservação e que se recorra, principalmente, às diversas provas de sua existência em conjunção da análise contextual.

Partindo desses pressupostos teóricos, entende-se que uma das possibilidades de investigação da cultura material têxtil no Brasil - dada a insuficiência de artefatos disponíveis para seu estudo, mas não só por essa razão - é por meio do acesso de outras fontes que se dirijam a eles, em associação aos dados históricos e sociais específicos. Por esse prisma, tomou-se como ponto de partida desta análise o modo de circulação de têxteis importados destinados ao consumo urbano no início do século XIX por meio dos anúncios de venda desses produtos nos comércios cariocas do período. $\mathrm{O}$ objetivo da análise é entender a circulação de têxteis em si mesma, bem como interpretar possíveis origens de práticas de apreciação de produtos estrangeiros, válidas inclusive na atualidade.

A adoção de novos hábitos de consumo que marcou esse período potencializou a dimensão simbólica dos têxteis, espécies materiais utilizadas como claro elemento de distinção social frente aos têxteis artesanais e domésticos mais característicos, que abasteciam a população rural ou mais pobre. Ainda que, visual ou materialmente, a comparação entre as diversas espécies disponíveis à época pudesse denotar essa constatação, ela surge de maneira mais impactante e 
evidente a partir da análise dos anúncios publicados para a divulgação dos tecidos estrangeiros e nacionais, nos quais as diferenças discursivas postulam as hipóteses anteriormente lançadas.

Almanaques comerciais ${ }^{1}$ publicados entre 1847 e as duas primeiras décadas do século XX anunciavam a oferta de diferentes tipos de têxteis por meio da descrição de suas qualidades. Nesses anúncios é possível encontrar diferenças alarmantes de atribuição qualitativa em função da origem dos produtos e de seus usuários legítimos, o que explica, ao menos parcialmente, nosso vínculo emocional com a produção e o consumo do produto estrangeiro, independente de seu valor intrínseco, por vezes questionados por fontes da história econômica, sendo Stanley Stein (1979) o precursor.

Os discursos comerciais sobre os têxteis, na forma de anúncios, que foram analisados não encobrem - ao contrário, expõem - as transformações da cultura material e do espaço simbólico que sofremos desde o século XVI, a partir do processo de penetração dos tecidos importados e do tipo de desenvolvimento desencadeado na indústria têxtil nacional. Tais situações refletem importantes questões de ordem econômica, política e técnica e, ao mesmo tempo, o processo de "colonização do imaginário" (Gruzinski, 2003) ao qual estivemos submetidos, indicando possíveis causas da dependência emocional em relação aos produtos estrangeiros que perdura ainda hoje.

\section{Cultura material têxtil no Brasil: transformações do espaço simbólico}

Entende-se que

A definição mais básica acerca do que é um têxtil, é que se trata de um material fabricado por algum tipo de processo de tecimento. Esta definição é derivada do latim, raiz da palavra "têxtil", textere, que significa tecer. O termo têxtil também pode ser aplicado a materiais manufaturados pelo entrelaçamento de fios, tais como objetos feitos pelo trançado, malharia e renda, bem como materiais não fiados, como feltros, nos quais as fibras ganharam coesão por tratamentos mecânicos ou processos químicos. Em casos raros, peles, couros e plásticos podem ser considerados têxteis, especialmente quando usados na manufatura de roupas (Leene, 1972, apud Bittner, 2004).

As tribos indígenas aqui residentes antes de 1500 já praticavam atividades de produção de objetos utilitários em barro, madeira, peles, fibras ou palhas 
vegetais, com os quais produziam, por meio de técnicas de tecelagem e trançado consideradas rudimentares, cestos, esteiras, redes, túnicas, entre outros. Essa pequena variedade de produção era suficiente para o assentamento das tribos, sem que a motivação produtiva fosse a atividade mercantil de seus produtos ou de suas habilidades.

Diz-se que quando os portugueses aqui desembarcaram, presentearam os índios com espelhinhos e outras quinquilharias que eles desconheciam. Os objetos teriam servido como instrumento de aproximação com as tribos que se dispuseram a auxiliá-los na exploração do território, em troca do pau-brasil e, também, como pagamento por serviços prestados antes da chegada dos escravos africanos.

O interesse dos nativos pelos objetos que lhes eram estranhos, no entanto, não deve ser atribuído somente a um possível encantamento com a materialidade ou técnica de fabrico de ditos objetos. Uma interpretação plausível, a partir da antropologia da cultura em Clifford Geertz, é que possivelmente os índios não tenham se apercebido dos diferentes níveis de complexidade ou elaboração de qualquer produto, pois não reconheciam o esforço científico, mas que tenham sido suficientemente sagazes para perceberem que novos usos e novos significados estavam atrelados a esses espécimes de cultura material. É desse ponto de vista que é possível considerar o contato com os objetos europeus, desde a sua chegada, como um processo de aculturação importante.

Devido ao caráter extrativista implantado durante a colonização e após o fracasso na tentativa de escravização dos nativos, optou-se pela utilização da mão de obra escrava oriunda da África, que passou a realizar o trabalho nas lavouras, entre outros. Deu-se também a presença dos primeiros europeus colonizadores que, na medida em que esgotavam os recursos da terra, transferiam-se para novos lugares e provocaram o surgimento de arranjos habitacionais com caráter instável, precário, provisório (Novais, 2002) e com pouco ou nenhum conforto.

Entende-se que a formação de tais núcleos habitacionais, por mais precários que pudessem ter sido, tenha aproximado os nativos a uma materialidade que não era comum ao ambiente rural (Alencastro; Renaux, 1997) e que se relacionava com novos modelos de conduta (Gruzinski, 2003), sinalizando que as distintas origens dos produtos demarcavam diferenças entre seus possuidores/usuários. No que tange especificamente aos tecidos, é sabido que, antes do primeiro desembarque dos portugueses, diferentes tribos indígenas praticavam a fiação e a tecelagem de algodão (Libby, 2007; Delson, 2004), e foi a ação missionária que insistiu em vesti-los, que tratou de atribuir ao uso das roupas uma exigência para a cristianização e, desse modo, provocou a transformação do olhar dos povos aqui residentes (Brust, 2007). Assim, comprova-se que as novas experiências sociais, por mais simples que pareçam, contribuíram para a construção da nossa relação com os objetos. 
Associado a hábitos estranhos aos nativos, o uso de tecidos desde o século XVI marcou diferenças entre as origens dos homens e, mesmo com a chegada dos escravos africanos - entre os quais alguns já tinham a vestimenta, bem como os tecidos simbolicamente adornados, incorporados às suas práticas culturais - a separação fortificou-se dentro do plano político para demarcar claramente as distinções sociais. A diferença transferiu-se do nativo/colonizador para o escravo/senhor.

Leis específicas concretizaram as distinções, impedindo que o que era considerado luxo fosse acessível a todas as classes sociais, ou, melhor dizendo, para escravos e senhores indistintamente. Para tal, além do decreto de 1749 que proibia que negros e mulatos utilizassem-se determinadas cores e tecidos, o primeiro deles que identifica o gosto pelo luxo desenvolvido na colônia data de $1696^{2}$ e afirma

[...] que sendo-lhe presente o demasiado luxo de usado no vestuário as escravas do Estado do Brasil, e devendo evitar-se este excesso e o ruim exemplo que dele se pode seguir foi servido resolver que as escravas de todo o Estado do Brasil em nenhuma das capitanias dele possam usar de vestido algum de seda, nem se sirvam das cambraias ou holandas, com rendas ou sem elas, para nenhum uso, nem também de guarnição de ouro ou prata nos vestidos.

Prova irrefutável, também, da insistência em manter a colônia e a grande maioria de seus habitantes afastados de quaisquer melhorias materiais com significados simbólicos, pois esse tipo de valor passava a significar divisas, é o famoso alvará de 1785 . No Brasil, além de manter-se a prática de tecelagem nativa, ampliara-se a produção de tecidos rústicos, ainda que esse tipo de atividade tenha sido considerada insignificante (Prado Jr., 1999), e também mantinha-se o comércio de tecidos contrabandeados (especialmente ingleses), que passou a incomodar a administração portuguesa, devido à diminuição de seus números de exportação e, em consequência, a produção das fábricas na metrópole.

Entendendo que essa situação prejudicava o desenvolvimento de Portugal, em 1785, Dona Maria I (1734-1816), rainha de Portugal, firmou decreto que proibia a fabricação na colônia de tecidos de ouro, prata, lã, linho, algodão e seda, só sendo permitido que as fábricas aqui instaladas produzissem as espécies mais grosseiras.

Esse alvará veio acompanhado de uma ordem de confisco aos teares instalados nas pequenas manufaturas que salpicavam nas capitanias. A alegação da Metrópole era que, "tendo os moradores da colônia, por meio da lavoura e da cul- 
tura, tudo quanto lhes era necessário, se ajuntassem a isso as vantagens da indústria e das artes para vestuário, ficarão os ditos habitantes totalmente independentes de sua capital dominante" (Holanda, 2004: 107). Esse fato contribuiu para que o desenvolvimento têxtil no Brasil fosse coibido por mais alguns anos, mas não se pode determinar que tenha sido sua causa única.

Esse conjunto de fatos e ordens - proibições, limitações, confiscos - torna evidente que antes do século XVIII, no Brasil, os aspectos intangíveis dos produtos despertavam o interesse da população, fosse ela negra, índia, branca ou miscigenada. No que diz respeito aos tecidos, à moda e aos costumes, o hábito indumentário europeu tornava-se referência de elegância e distinção, o qual permitia que diferenças entre os grupos sociais também pudessem ser verificadas e reconhecidas pela origem e pelo tipo dos tecidos adquiridos pelos indivíduos.

A preocupação com a aparência está alinhada com o crescimento populacional do final deste século, quando também foi ampliada a população de trabalhadores com rendimentos. Nesse período, surgiram novas instalações mais perenes, o que ampliou a demanda por têxteis necessários à composição dos lares e, também, para o vestuário. Para suprir o primeiro surto de consumo interno, tais mercadorias poderiam ser obtidas somente por duas vias: ou chegavam da Europa (via comércio legal ou contrabando) em navios, com espécies sempre insuficientes à demanda existente, ou eram produzidos no vácuo provocado por essa insuficiência, em instalações acessórias a outros empreendimentos, em manufaturas domésticas ou, ainda, em pequenos negócios industriais que começavam a se estabelecer (Prado Júnior, 1999).

Enquanto as espécies mais finas e nobres, reservadas às classes mais abastadas, continuavam a ser fornecidas sobretudo pelas importações,

[...] os portos de Pernambuco e Bahia tornaram-se escalas obrigatórias das naus que voltavam do Oriente, abarrotadas de mercadorias de valor, como sedas e veludos. Gabriel Soares, aludindo ao luxo nos engenhos de açúcar e fazendas, diz que “... as mulheres não vestiam, senão seda ...”, consequência, por certo da prosperidade trazida pelo açúcar e pelo trabalho do braço escravo (Barros, 1947: 120).

Os tecidos grosseiros destinados aos homens escravos ou livres das classes mais pobres continuavam a ser produzidos pelas manufaturas locais, ainda que, no século XIX, já se apontasse para a existência das primeiras "indústrias nacionais".

O movimento progressivo da indústria na segunda metade do século XIX foi constante graças ao tipo de tecido produzido pelas primeiras fábricas 
têxteis. Com efeito, elas aprovisionaram o maior mercado disponível na economia de um país subdesenvolvido do século XIX: roupas para os trabalhadores, escravos e livres, da cidade e do campo; panos para ensacar açúcar e, particularmente, o café exportado em quantidade cada vez maior (Stein, 1979: 38).

Os produtos nacionais definitivamente delimitaram-se às espécies vulgares, destinados a um mercado certo de sacarias e tecidos para as roupas dos escravos. A chegada da família real tinha aberto nova perspectiva à industrialização, pois, com o objetivo de promover nosso desenvolvimento, diferentes iniciativas tomadas por Dom João VI (1767-1826) e suas respectivas consequências estimularam, ou ao menos não mais impediram, o aprimoramento das indústrias no Brasil. A revogação do alvará de 1785 que proibia a produção de manufaturas diferenciadas, a abertura dos portos para o comércio com as nações amigas, a concessão de terras aos estrangeiros, o crescimento da imigração europeia, a diminuição do trabalho escravo, o declínio do patriarcado rural e o aparecimento do patriarcado urbano (Barros, 1947) facilitaram a industrialização da colônia.

A mudança da composição da sociedade também contribuiu para o estabelecimento das condições minimamente necessárias para a ampliação da circulação de mercadorias diferenciadas, fornecidas pelas importações estrangeiras intensificadas pela abertura dos portos. A chegada da corte foi o primeiro choque cultural vivenciado na colônia e

[...] representou a oportunidade para a renovação dos costumes. Oliveira Lima calculou em 50 mil o número de pessoas transmigradas com a família real. A presença de gente nova trazia novas oportunidades comerciais [...]. Em consequência, os próprios habitantes da terra passaram a adotar costumes, até então desconhecidos no meio colonial (Barros, 1947: 147-148).

Outra grande transformação, sentida posteriormente, teve como ponto de partida os surtos migratórios europeus. Se, segundo Alencastro e Renaux (1997), quatro milhões de africanos foram trazidos para o Brasil até 1850, nos cem anos seguintes, cinco milhões de europeus, levantinos e asiáticos substituíram plenamente o trabalho escravo. Estima-se que a presença de pessoas que já estavam acostumadas ao consumo de diversas qualidades de produtos industrializados movimentou o mercado de exportações e, dessa maneira, a necessidade de expansão da indústria nacional fez-se evidente.

A passagem do Brasil de senhores e escravos à reprodução da estratificação social europeia, que já contava com a presença da burguesia, também é um dos elementos que nos conduziu à modernidade em seus aspectos sociais: 
[...] os valores de mobilidade e distinção dentro da estrutura social, de identificação pelo (bom) gosto e pelo consumo de mercadorias revestidas de valores ideológicos, entre outros, preponderaram como a realidade desse novo sistema (Rezende, 2003: 85).

Não se deve interpretar, no entanto, que o crescimento do setor produtivo fez-se repentinamente. Segundo Canabrava (1984), no ano de 1866 existiam no país apenas nove fábricas de tecido em funcionamento e todas elas, mais as que foram surgindo nos anos seguintes, voltavam-se para a produção de tecidos grossos e resistentes, ainda preferidos pela maioria da população (Stein, 1979). Na verdade, outra possibilidade aventada é que tais tecidos, sobre os quais as indústrias tinham domínio da técnica de produção, foram os que vieram a representar definitivamente o tipo de produto que o Brasil produzia, impedindo de associar nossa nação à produção de têxteis diferenciados. Mesmo no período denominado "os anos dourados" por Stein (1979), marcado pelas duas primeiras décadas do século XX e pelo fim da Primeira Guerra Mundial, quando a produção nacional passou a cobrir até $85 \%$ do consumo local, o lugar reservado aos tecidos de luxo continuava a ser ocupado pelos produtos estrangeiros. Nesse momento, dominávamos o mercado popular e somente a melhor qualidade dos produtos importados podia concorrer no Brasil (Stein, 1979), pois mesmo entre as espécies estrangeiras "havia os superiores e os inferiores ou ordinários" (Januário, 2006: 178).

Assim como a distinção entre nativos e colonizadores (Novais, 2002) representava classes de indivíduos, a procedência dos objetos acompanhou esse raciocínio até recentemente. Os tecidos nobres, assim, receberam de pronto predicados de procedência, tais como "importado", "estrangeiro", "inglês" e "francês", e as referências aos tecidos dos trabalhadores marcavam, sobretudo, a questão funcional, estando sujeitos à descrição ${ }^{3}$ de "tecidos para pessoas de cor", "tecidos pesados adequados para as classes da sociedade menos favorecidas pela sorte", "mercadoria ordinária usada pelos nativos das classes mais pobres", entre outras. Desse modo, qualquer expressão vinculada ao produto nacional ou "da terra" adquiria conotação pejorativa, indicando, para além de uma "classe de produtos" sem qualidades nobres, apenas funcionais, uma "classe de pessoas" sem prestígio algum.

\section{Processos de legitimação das distinções}

Tanto o percurso econômico dos têxteis no Brasil quanto o simbólico foram pautados, como pôde ser visto, pela ênfase na distinção social. Para tal, a Me- 
trópole impôs leis e medidas econômicas que interferiram diretamente no desenvolvimento técnico e comercial da Colônia, e também se manifestou a sanção moral, étnica e cultural, por meio da aculturação ou segregação dos colonos e nativos.

Nos primeiros séculos de colonização, as distinções foram conduzidas, com o apoio do uso da palavra, em sua aplicação nos decretos ou, oralmente (especialmente a catequese), nas relações de poder que se estabeleceram internamente, como provam, principalmente, os decretos de 1696, 1749 e 1785 . Com a chegada da família real portuguesa em 1808, a mesma dinâmica passou a tomar parte dos argumentos do comércio em expansão e invadiu as páginas impressas de jornais, revistas e almanaques comerciais publicados a partir do segundo quartel do século XIX, procedimento comum por mais de cem anos.

Entretanto, $\mathrm{o}$ analfabetismo no Brasil teve índices alarmantes até aproximadamente 1950, e a leitura era considerada um hábito de elite. A circulação da palavra impressa sempre atingiu somente um pequeno número de cidadãos que, em sua maioria, habitavam os ambientes urbanos. E, uma vez que a circulação de imagens impressas (especialmente a fotográfica) no Brasil ao longo do século XIX não era corriqueira, pode-se entender que a cultura da palavra adquiriu importância destacada e tornou-se elemento fundamental na descrição ou qualificação de produtos e costumes.

Tanto a imprensa nacional quanto a circulação de revistas estrangeiras contribuíram para promover nossa modernização social (Cardoso, 2004), sendo co-responsáveis pela divulgação e pela penetração dos valores europeus no Brasil como signos de distinção. Tratando-se, os tecidos, de exemplares da cultura material e aptos a representar, por meio de suas características e trajetórias (Appadurai, 1986), os valores predominantes, observa-se que sua descrição é construída, principalmente, a partir da exaltação da procedência, do bom gosto, estilo e apuração de hábitos sociais, e presente, mas em menor escala, na supremacia da produção moderna e industrial, que representa virtuosidade técnica de produção e produto.

São diferentes os tipos de anúncios encontrados nos almanaques comerciais, a depender, provavelmente, do tamanho da casa comercial e, também, do tipo de comércio. No início do século XX, a maioria delas dedicava-se somente à comercialização de tecidos brasileiros, pois se estabelecia, pouco a pouco, a prática de unir a atividade comercial à industrial (Graham, 1973), como estratégia eficiente para proteger o mercado interno da invasão dos produtos estrangeiros.

Tomar as palavras descritivas e predicativas dos produtos têxteis como detentoras de algum poder simbólico supõe considerar os veículos que as suportam como legitimamente reconhecidos pelos sujeitos em interação (Bourdieu, 
2005). Assim, revistas e jornais do século XIX equivalem-se, socialmente, às leis e aos decretos dos séculos precedentes e configuram, de certa forma, valores predominantes.

Os anúncios estudados não apontam a existência de diferenças substanciais que justifiquem sua discussão à luz de uma análise cronológica. Os símbolos de distinção presentes nas leis não se esgotaram até, pelo menos, os anos 20 do século XX, quando movimentos artísticos pró-modernidade, cujo marco é a Semana da Arte Moderna de 1922, propuseram um novo lugar ou, pelos menos, uma nova discussão para a influência estrangeira sobre a cultura nacional.

$\mathrm{Na}$ forma de discurso indireto das crônicas sociais e de manuais de comportamento ou, no discurso direto, presente na publicidade comercial, as palavras revelaram-se instrumentos de inclusão e exclusão social, ou seja, símbolos de status. Se, ao descrever produtos estrangeiros as qualidades mencionadas eram inúmeras e, os tecidos nacionais, por outro lado, tinham como diferencial sua resistência, associada ao trabalho duro, feito com as mãos e solenemente desclassificado, a distinção entre seus usuários também é clara.

Por esse prisma, classes de produtos existiriam apenas para atender a diferentes classes de pessoas. É, ainda, a partir de evidências de que em ocasiões especiais, ou até mesmo no dia a dia, os mais pobres poderiam vestir-se com tecidos melhores e endomingarem-se, promovendo certo trânsito social, ${ }^{4}$ possível por meio da utilização dos tecidos como sinais exteriores, que ocupam transitoriamente o lugar da pele, determinando o espaço que cada indivíduo poderia ocupar. Podemos ler, simultaneamente, nos discursos sobre os produtos, o prestígio e o desprestígio, o conceito de estrangeiro em oposição ao nacional e/ou o de urbano em oposição ao rural (o que equivale ao de homem estrangeiro, livre, senhor ou, ainda, o citadino, sobreposto ao de homem negro ou trabalhador braçal ou, também, ao homem rural), o valor estético em oposição ao valor funcional e/ou o fino em oposição ao grosseiro (o que equivale ao burguês em oposição ao trabalhador braçal) e, finalmente, a produção industrial em oposição ao fabrico rudimentar e/ou o mais moderno em oposição ao mais antigo (o que equivale a opor homem intelectual ao homem ignorante).

Todos eles, verifica-se, situam-se no âmbito das restrições que permitem a visualização da distinção social e, de acordo com categorização proposta por Goffman (1951), correspondem a diferentes maneiras de se construir a raridade, elemento-chave da imputação de valores, já que marca a dificuldade de alcance do objeto pelo sujeito. Restrições naturais, sociais e intrínsecas (Goffman, 1951) são determinadas por adjetivações distintivas de origem, por inadequações funcionais simbolicamente inacessíveis àqueles "menos favorecidos pela sorte", nas palavras de Stein (1979). 
Figura - Anúncio publicado em 1853 para Alexandre Castel \& $\mathrm{C}^{5}$

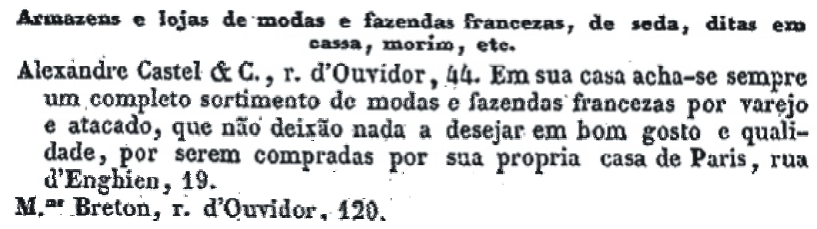

Figura - Anúncio publicado em 1853 para Wallerstein, Masset \& $\mathrm{C}^{6}$

\section{WALLERSTUN, HASSET \& G. \\ 70 RUA DO OUVIDOR 70}

Com casa em Paris e cm Londres, recebem fazendas por todos os vapores de.Southampton, assim como por todos os paquetes regulares do Havre, encarregão-se de qualquer encommenda, tanto para Franca, como para Inglaterra; enconti'a-se scmpre nos seus armazens grande sortimento de lazendas francezas, inglezas e da India ; toda a qualidade de artigos proprios para o toilette de uma senhora, sedas, Iũas, cassas, meias, rendas, modas, emfin tudo que apparece de novidade; algumas vezes ainda antes de conhecidas e vistas em Paris, sũo immediatamente remettidas pclos vapores; artigos de todas as qualidades para homens e meninus, chapíos e bonés, pannos, casimiras, brins, fazendas para colletes, granile sortimento de camisas, roupa feita, luras, meias, etc., morins c linhos, lentes de linho, cambraia e seda da India, leques, oculos para theatro, lencos, camisinhas bordadas, \&c.

Figura - Em 1854, para J. R. Soares ${ }^{7}$

\section{1.}

95 RUA DA QUitanda 95

SUCCESSOR DE MANOEL JOSÉ DE ARAUJO COSTA \& C.

ESTABELECIMENTO DE FAZENDAS

Com um sortimento geral de sedas, lãas, linhos e algodões, e outros objectos proprios para senhoras e homens, contendo:

3283

mais recentes chegadas da Europa, assim como differentes arligos

DA Canva

em. sedas e charão.

A exaltação da procedência - por meio de adjetivações como "tecidos ingleses", "tecidos franceses", "tecidos importados", "concorrência com os mais acreditados estabelecimentos da Europa"; sistemas de aquisição, como "importação direta"; "compras na Europa"; "recebidos por todos os paquetes e navios" - ou, ainda, a utilização de nomenclatura em idioma estrangeiro ou aportuguesamento por corruptela -"baeta"/baize, "casimira"/cashmere, "tafetá"/tafetta e outros - define claramente a origem não-brasileira dos produtos. 
Figura - Em 1880, em anúncio para A La Ville de Bruxelles ${ }^{8}$

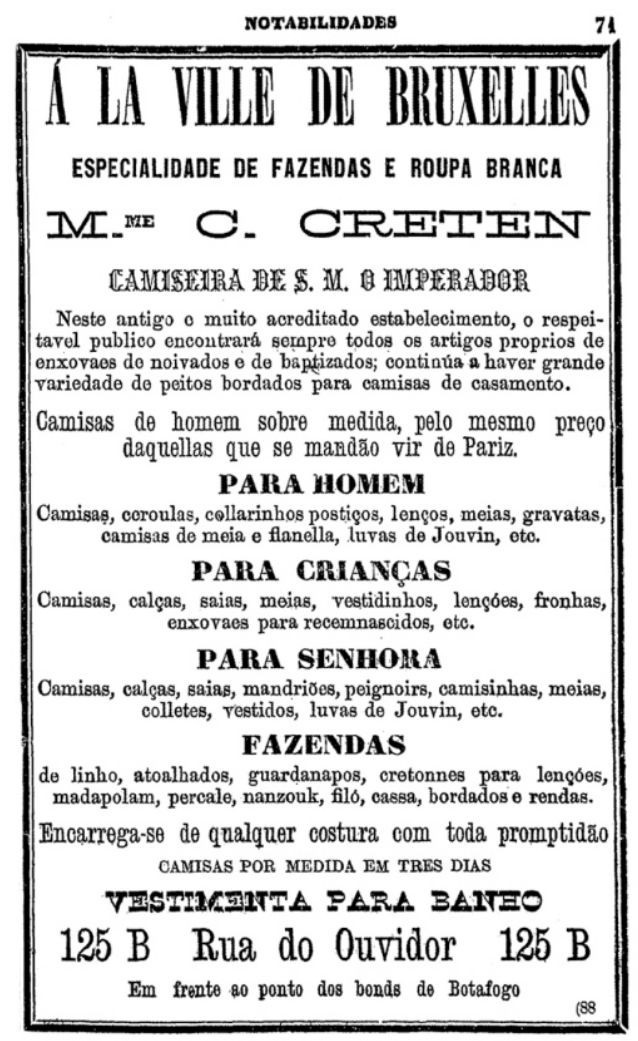

O julgamento estético relacionado ao domínio sobre o belo e a associação do uso ao ócio e ao prazer também marcaram os tecidos importados. Narrativas similares a "bom gosto", "grande e variado sortimento" e "todas as qualidades" para designar a existência de muitas opções que vão além do tecido simples e "sem nenhuma variedade" (Stein, 1979) de produção nacional coincidem com o surgimento de ocasiões para a utilização de tecidos especiais, aplicados em "vestidos para baile", "batizados", "luto", "artigos para toillete”, agora necessários, já que a vida social e cultural se ampliava. Por fim, o desejo de antecipar-se à moda local para equiparar-se à temporada europeia pode ser comprovado pelas descrições de "última moda", "nunca antes visto em Paris" e "capaz de satisfazer as mais difíceis exigências", que indicam claramente uma estratégia apelativa, descolada do produto em si e totalmente baseada em valores extrínsecos. 
O desejo de sentir-se moderno e o de fazer parte do progresso são os únicos discursos pontuados nas práticas fabris com potencialidade para serem avaliados concretamente, ainda que se estime que alguns não correspondam exatamente à realidade dos fatos. A descrição de técnicas e da velocidade de produção, bem como da especialização da mão de obra marcam uma aproximação do sentido de qualidade dos produtos à visão moderna, ou seja, não única e exclusivamente dependente de fatores estéticos, mas também relacionada aos processos produtivos. Vemos, portanto, argumentos como "reforma" das máquinas e estabelecimentos, "novos processos"; "mais hábeis oficiais de Paris", "perfeição no trabalho", "cores inalteráveis" e "primeiro do gênero no Brasil", para incluir o sistema produtivo no debate sobre o produto.

Figura - Anúncio de 1880 de fábrica nacional

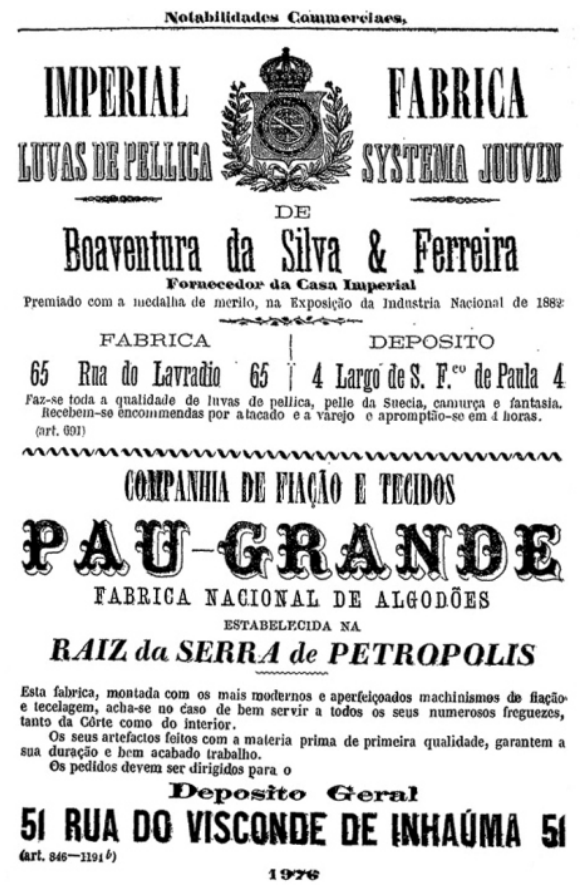

Os tecidos nacionais, de maneira geral, são descritos até o final do século XIX, quando aparecem timidamente nas páginas dos almanaques comerciais. Essa posição justifica-se em tom especulativo, dado que, em teoria, os leitores pertenceriam às classes mais abastadas $\mathrm{e}$, portanto, não haveria necessidade ou sentido em anunciar produtos ordinários. 
O produto brasileiro começou a aparecer nos anúncios comerciais somente na fase de industrialização (como negócio) mais próspera, quando já chegava a dominar mais de $3 / 4$ do mercado em geral (Stein, 1979). Devido, também, à importação de produtos estrangeiros medíocres, a produção nacional teve a oportunidade de se manifestar em oposição a ela, ou seja, alertando o consumidor que os produtos estrangeiros não detinham as mesmas qualidades do produto nacional, especialmente a resistência. Esse fato é comprovado pela ampliação da inserção dos tecidos brasileiros nos centros urbanos e nas áreas rurais, pelo contingente de mão de obra contratado pela indústria têxtil e pela participação e mérito recebidos pelas manufaturas brasileiras nas Grandes Exposições. O prestígio do tecido nacional alcançou um nível de destaque importante, a ponto de os tecidos estrangeiros nomearem-se, algumas vezes, falsamente como nacionais para incorporar tais valores (Stein, 1979).

Tanto a argumentação sobre a composição quanto a própria valorização da resistência não merecem, no entanto, maiores discussões porque simplesmente parecem descritivas dos produtos fabricados. Por outro lado, o destaque dado ao progresso industrial e ao ideal nacionalista situa-se num lugar que jamais poderia ser ocupado pelo produto estrangeiro, fazendo com que tal fato seja digno de menção e foco de atenção para futuras investigações.

Hardman, por exemplo, aponta o interesse do Brasil em participar das Exposições Universais como marco que evidencia a busca da identidade nacional:

Exposições Universais: um nome para cada coisa, um lugar para cada nome e para cada coisa, um tempo-espaço para exibir os resultados. O Brasil, desde 1861, candidatou-se a tomar parte ativa nessa representação. Catalogou tudo que podia; decorou seus compartimentos; entrou na cena do desfile mundial das mercadorias; completava-se, assim, o ritual de passagem que o fazia atuar por inteiro no concerto das nações. A imagem do país moderno dessa forma se construía. Já era possível se mostrar in totum e nos detalhes. Até as fraturas estavam expostas (Hardman apud Rezende, 2003: 125).

Participar de tais exposições - e a menção a elas e à premiação recebida surge, muitas vezes, nos anúncios estudados - demonstra que o nacionalismo foi além da expressão artística, sobretudo aquele presente na literatura romântica e na pintura. Na comunicação relacionada à indústria, o nativismo fez-se presente nas embalagens de produtos industrializados ${ }^{9}$ (Cardoso, 2005), mas a publicidade estudada revelou apenas os aspectos do patriotismo: "sentimento de apreço pelo jovem Brasil e sua formação institucional, mais ligado aos centros urbanos, à polis (Rezende, 2003: 100). 
É difícil sugerir quais as razões que tenham promovido o encaminhamento desse discurso, diferenciando-o totalmente do seu concorrente. É possível que tenha seu fundamento na ideia de uma teoria econômica que desbancou na metade do século XIX o senso comum que vigorava até então, o de que o país era predestinado somente à agricultura (Stein, 1979). Pelo contrário, novas análises desde então faziam crer que o desenvolvimento da indústria promoveria o aumento do comércio e da agricultura.

Pode ser, de fato, que o nível de industrialização em aprimoramento tenha sido interpretado, conforme relatório apresentado pelo Ministério da Agricultura, como uma vitória inesperada:

Rio de Janeiro, 4 de fevereiro de 1887

A indústria fabril de tecidos de algodão, depois de lutar algum tempo com as maiores dificuldades, acarretando prejuízos a muitos de seus iniciadores, conseguiu finalmente vencer em grande parte a concorrência estrangeira, e vai progredindo de modo satisfatório, tendo já produzido, entre outros benefícios, o de fazer baixar o preço dos tecidos grossos, consumidos, em larga escala, pelas classes menos favorecidas da fortuna.

É mais fácil acreditar, a partir dessa conjectura, que a exaltação do nacionalismo conferia com a crença no projeto de industrialização e desenvolvimento e não, apenas, um ato de conformidade com seu destino limitado a produtos e usuários desprestigiados. Nas décadas seguintes, nas quais se verifica muitas vezes uma postura xenófoba, o discurso não foi o de valorização do nacional, mas de desprestígio do estrangeiro (antes improvável, devido às características políticas de nosso Império), de maneira que o momento estudado revela características particulares, coincidentes com um momento de transição e, até mesmo, de determinação de ponto de vista. Descobrir-se é, também, uma tarefa de construção. Como afirma Bourdieu: "por mais objetiva que a identidade possa ser, ela é objeto de representação mental, de atos de percepção e apreciação, conhecimento e reconhecimento" (2005: 112).

Por outro lado, na maior parte do período estudado, a produção nacional praticamente não é descrita. Justificando-se, talvez, pela falta de interesse em produzir anúncios comerciais para uma classe de consumidores, em sua maioria, analfabetos, só começam aparecer algumas poucas palavras atribuídas aos tecidos nacionais nas duas últimas décadas do século XIX, revelando, quase sempre, os mesmos valores que eram necessários quando se destinava exclusivamente a uma utilização acessória. 
Entre a enorme quantidade de anúncios de fábricas ou casas comerciais de tecidos publicados no Almanak Laemmert, grande parte daqueles que operam os tecidos importados, como pôde ser visto, explora as palavras em toda a sua magnitude. Percebe-se que os tecidos nacionais são tratados de maneiras diferentes: simplesmente não descritos; (a) menção às suas fibras e/ou cores; (b) valorização da resistência ao uso e à lavagem; e algumas (c) indicações de destino aos escravos ou criados. Está presente, no entanto, a (d) ideia progressista e nacionalista nos nomes dos estabelecimentos ou na chamada publicitária.

\section{Considerações finais}

Existe uma certa acomodação, ou um certo desconforto, com este discurso distintivo que diz respeito à origem dos produtos e, raramente, tenta-se compreender porque ele se estabeleceu entre nós. O que estes anúncios demonstraram, na prática, é o que Rezende identificou abaixo:

[...] os bens de consumo que a sociedade brasileira importava vinham acompanhados de um outro valor, um tanto imaterial, mas não menos importante: a cultura burguesa. Inicialmente a cultura francesa com algumas doses da inglesa. Sua medida estava por toda a parte na qual a elite desfilava. No vestuário, notadamente incômodo para a realidade tropical úmida e quente, porém transposto peça por peça, tecido por tecido para significar elegância e distinção (2003: 8).

Essa ideia é reforçada por Januário, a partir da

[...] obsessão pela distinção, partilhada entre segmentos sociais em seus vários níveis de riqueza, que a variedade de tecidos finos e rústicos, caros e baratos, nacionais e importados em suas variadas cores e estampas, entraram no cenário desta luta surda, no sentido de manter os afastamentos quando houvesse as aproximações daquela sociedade essencialmente desigual, garantindo a manutenção e o reconhecimento de sua posição social nas Minas Gerais [extensivo ao Brasil] através da aparência e das exibições públicas (2006: 179).

O que não pode ser esquecido na análise dessa prática, principalmente no contexto contemporâneo, é que, tomados isoladamente, os artefatos, em si 
mesmos, não proferem discursos. Uma vez que as palavras dos indivíduos é que recaem sobre eles [nós], elas são as responsáveis por representar objetos e seus possuidores em instâncias simbólicas, nas quais reside o conceito de valor que,

[...] para Simmel, nunca é uma propriedade inerente aos objetos, mas é um julgamento feito ao seu respeito pelos sujeitos. Assim, a chave para a compreensão do valor, de acordo com Simmel, encontra-se em uma região onde "a subjetividade é somente provisória e realmente não muito essencial” (Appadurai, 1986: 3).

Narrativas e coisas estão, assim, definitivamente associadas, porque os objetos anônimos, como os têxteis em questão, não só circulam sob manifestos ou propostas artísticas, como também existem plenamente, independentemente do valor que lhes é dado pelo humano por meio da linguagem (Appadurai, 1986). Segundo Prown (1982), na perspectiva da cultura material, o objeto é estudado a partir do ambiente cultural no qual circula, já que cada sociedade expressa o seu estilo nas coisas. Procura-se, a partir de uma "aproximação emotiva", "a objetividade do método científico" (Prown, 1982: 5). A circulação dos objetos não está divorciada jamais das normas sociais, políticas ou culturais vigentes (Appadurai, 1986).

\section{Notas}

1. Os fascículos do Almanak Laemmert e da revista Fon-Fon estão disponíveis no site da Biblioteca Nacional. Acesso em www. bn.br. O almanaque foi publicado no Rio de Janeiro entre 1844 e 1889, com anúncios da Corte e também como guia comercial. A Fon Fon, por sua vez, foi publicada também no Rio de Janeiro, entre 1907 e 1958, e caracteriza-se como uma revista de amenidades e notícias, com anúncios comerciais que revelam o gosto e os costumes do período.

2. Decreto firmado em 20 de fevereiro de 1696. Fontes diversas, sem localização do documento original.
3. Todas as descrições apontadas são utilizadas por Stein (1979) ao longo de seu livro.

4. O conceito de roupa como sinal exterior e que contribui para o trânsito social, especialmente no ambiente urbano, onde o contato entre as pessoas é superficial, foi estudado com ênfase na experiência brasileira por Gilda Rocha de Mello e Souza em sua tese de doutorado, defendida em 1950 na Faculdade de Filosofia, Letras e Ciências Humanas da Universidade de São Paulo. 
5. Em 1853, foi publicado o seguinte para Alexandre Castel \& C: Em sua casa acha-se sempre um completo sortimento de modas e fazendas francesas [...] que não deixam a desejar em bom gosto e qualidade por serem compradas por sua própria casa de Paris, rua d'Enghien 19 (grifo meu).

6. Com casa em Paris e em Londres, recebem fazendas por todos os vapores de Southampton, assim como por todos os paquetes regulares do Havre, encarregam-se de qualquer encomenda, tanto para França, como para Inglaterra; encontram-se sempre nos seus armazéns grande sortimento de fazendas francesas, inglesas e da Índia: toda a qualidade de artigos próprios para o toillete de uma senhora; sedas, lãs, cassas, meias, rendas, modas, enfim, tudo que aparece de novidade; algumas vezes ainda antes de conhecidas $e$ vistas em Paris, são imediatamente remetidas pelos vapores [...] lenços de linho, cambraia e seda da Índia, leques, óculos para teatro $[. .$.$] ( grifo meu).$

7. ESTABELECIMENTO DE FAZENDAS. Com um sortimento geral de sedas, lãs,

Referências bibliográficas

ALENCASTRO, Luís Felipe de \& RENAUX, Maria Luiza. Caras e modos dos migrantes e imigrantes. In: ALENCASTRO, Luís Felipe de. História da vida privada no Brasil. Império: a corte e a modernidade nacional (vol. 2). São Paulo: Companhia das Letras, 1997, p. 291-336.

ANDRADE, Rita. Por debaixo dos panos: cultura e materialidade de nossas roupas e tecidos. In: PAULA, Teresa Cristina Toledo de. Tecidos e sua conservação no Brasil: museus $e$ coleções. São Paulo: Museu Paulista da USP, 2006, p. 72-76. linhos e algodões, e outros objectos próprios para senhoras e homens, contendo: LES NOUVEAUTÉS mais recentes chegadas da Europa, assim como diferentes artigos $D A$ CHINA em sedas e charão (grifo meu).

8. CAMISARIA DE S. M. O IMPERADOR. Neste antigo e muito acreditado estabelecimento, o respeitável públicoencontrará sempre todos os artigos próprios de enxovaes de noivados e de baptizados; continúa a haver grande variedade de peitos bordados para camisas de casamento. Camisas de homem sobre medida, pelo mesmo preço daquellas que se mandão vir de Pariz [...] (grifo meu).

9. O crescimento da indústria e a concorrência entre as marcas fizeram surgir a identidade visual nas embalagens com o objetivo de diferenciar um fabricante de outro. No Brasil, isso só ocorreu no início do século XIX e muitas marcas caracterizavam-se pela ideia nacionalista, exibindo, muitas vezes, rótulos bilíngues.

APPADURAI, Arjun. The social life of things. Commodities in cultural perspective. Nova York: Cambridge, 1986.

BARROS, Sigrid Porto. A condição social e indumentária feminina no Brasil-Colônia. Anais do Museu Histórico Nacional, VIII, 1947, p. 117-154.

BITTNER, Elizabeth. Basic Textile care: structure, storage, and display. Apostila da disciplina "Introduction to the Structure and Technology of Records Materials". Austin,Texas: Universidade do Texas, 2004. 
BOURDIEU, Pierre. O poder simbólico. Rio de Janeiro: Bertrand Brasil, 2005.

BRUST, Monique. Corpo submisso, corpo produtivo: os jesuítas e a doutrinação dos índígenas nos séculos XVI e XVII. Aulas, $\mathrm{n}^{\circ}$ 4, abril- julho 2007, p. 1-31.

CANABRAVA, Alice P. O algodão em São Paulo: 1861-1875. São Paulo: T. A. Queiroz, 1984.

CARDOSO, Rafael. O design brasileiro antes do design: aspectos da história gráfica, 18701960. São Paulo: Cosac Naify, 2005.

. Uma introdução à história do design. $2^{\mathrm{a}}$ ed. São Paulo: Edgard Blucher, 2004.

DELSON, Roberta Marx. The origin of Brazil's textile industry: an overview. National overviews Brazil, Textile conference IISH, 2004.

GOFFMAN, Erving. Symbols of class status. The Britsh Fournal of Sociology, 1951, p. 294-304.

GRUZINSKI, Serge. A colonização do imaginário. Sociedades indígenas e ocidentalização no México espanhol. Séculos XVI-XVIII. São Paulo: Companhia das Letras, 2003.

HOLANDA, Sergio Buarque de. Raízes do Brasil. São Paulo: Companhia das Letras, 2004.

JACKSON, Lesley. 20th Century pattern design. Textile Evwallpaper pioneers. Londres: Octopus Publishing Group Ltd., 2002.

JANUÁRIO, E. A. Os tecidos e sua função nas Minas Gerais colonial. In: Tecidos e sua conservação no Brasil: museus e coleções. São Paulo: Museu Paulista - Universidade de São Paulo, 2006, p. 178-181.

MELLO E SOUZA, Gilda de. $A$ moda no século XX. Ensaio de sociologia estética. Tese defendida na Faculdade de Filosofia, Ciências e Letras da Universidade de São Paulo FFCL-USP, São Paulo, 1950.
MENESES, Ulpiano Bezerra de. Fontes visuais, cultura visual, história visual. Balanço provisório, propostas cautelares. Revista Brasileira de História, vol. 23, $\mathrm{n}^{\circ} 45,2003$, p. 11-36.

NOVAIS, Fernando. Condições da privacidade na colônia. In: MELLO E SOUZA, Laura D. História da vida privada no Brasil. Cotidiano e vida privada na América Portuguesa São Paulo: Companhia das Letras, 2002, p. 13-.40

PAULA, Teresa Cristina Toledo de. Inventando moda e costurando história: pensando a conservação de têxteis no Museu Paulista/USP. Dissertação (Mestrado em Comunicações e Artes), Universidade de São Paulo, São Paulo, 1998.

Tecidos e sua conservação no Brasil: museus e coleções. São Paulo: Museu Paulista da USP, 2006.

PRADO Jr., Caio. Formação do Brasil contemporâneo: colônia. São Paulo: Brasiliense, 1999.

PROWN, Jules David. An introduction to material culture theory and method. Winterthur Portfolio, vol. 17, $\mathrm{n}^{\mathrm{o}}$ 1, 1982, p. 1-19.

REZENDE, Livia Lazzaro. Do projeto gráfico e ideológico. A impressão da nacionalidade em rótulos oitocentistas brasileiros. Dissertação (Mestrado em Design) Programa de PósGraduação em Design, Pontifícia Universidade Católica, Rio de Janeiro, 2003.

SCHOESER, Mary. World textiles. A concise history. Londres: Thames \& Hudson, 2003.

STEIN, Stanley. Origens e evolução da indústria têxtil no Brasil 1850-1950. Rio de Janeiro: Campus, 1979.

TILLEY, Christopher; WEBB, Keane; KUECHLER-FOGDEN, Susanne; ROWLANDS, Mike \& SPYER, Patricia. Handbook of material culture. Londres: Sage, 2006. 


\title{
Resumo
}

Ao final do século XIX, o processo de urbanização no Rio de Janeiro, demandou grande variedade de produtos industrializados para atender aos novos hábitos de socialização. Estabeleceu-se a importação e o comércio de tecidos ingleses e franceses, já que a indústria nacional não dispunha de tecnologia para sua produção. A partir da análise dos discursos encontrados nos anúncios comerciais publicados no período, demonstra-se que a procedência dos artefatos tornou-se importante elemento de distinção social sem relação com seu valor intrínseco.

Palavras-chave: cultura material têxtil; distinção social; anúncios de tecidos.

\begin{abstract}
At the end of the XIX century, Rio de Janeiro's urbanization process has demanded a large quantity of manufactured artifacts to attend the new socialization habits. Fabrics from England and France were imported and marketed, due to the lack of proper technology to produce fine quality fabrics in the Brazilian industry. By analyzing the discourses used in commercials of this period, one can demonstrate that the origin of the textile artifacts was turned into an important element of social distinction, without any relation with its intrinsic value.
\end{abstract}

Key words: textile's material culture; social distinction; fabrics advertisings.

\begin{abstract}
Résumé
À la fin du XIXe siècle, le développement de l'urbanisation du Rio de Janeiro a exigé une grande variété de produits industrialisés pour répondre aux nouvelles habitudes de socialisation. L'importation et le commerce des tissus anglais et français se sont établis, parce que la branche de production nationale n'avait pas la technologie pour cette production. À travers l'analyse des discours trouvés aux annonces publicitaires publiées dans la période, la recherche démontre que la provenance de ces produits est devenue un élément important pour la distinction sociale, à part le valeur intrinsèque de ces textiles.
\end{abstract}

Mots-clés: culture matérielle textile; distinction sociale; publicités pour les tissus. 